\title{
Effect of bisphosphonate treatment of titanium surfaces on alkaline phosphatase activity in osteoblasts: a systematic review and meta-analysis
}

Christian Wehner ${ }^{1}$, Stefan Lettner ${ }^{2,3}$, Andreas Moritz $^{1}$, Oleh Andrukhov ${ }^{1 *}$ and Xiaohui Rausch-Fan ${ }^{1}$

\begin{abstract}
Background: Bisphosphonate coating of dental implants is a promising tool for surface modification aiming to improve the osseointegration process and clinical outcome. The biological effects of bisphosphonates are thought to be mainly associated with osteoclasts inhibition, whereas their effects on osteoblast function are unclear. A potential of bisphosphonate coated surfaces to stimulate osteoblast differentiation was investigated by several in vitro studies with contradictory results. The purpose of this systematic review and meta-analysis was to evaluate the effect of bisphosphonate coated implant surfaces on alkaline phosphatase activity in osteoblasts.

Methods: In vitro studies that assessed alkaline phosphatase activity in osteoblasts following cell culture on bisphosphonate coated titanium surfaces were searched in electronic databases PubMed/MEDLINE, Scopus and ISI Web of Science. Animal studies and clinical trials were excluded. The literature search was restricted to articles written in English and published up to August 2019. Publication bias was assessed by the construction of funnel plots.

Results: Eleven studies met the inclusion criteria. Meta-analysis showed that coating of titanium surfaces with bisphosphonates increases alkaline phosphatase activity in osteoblasts after 3 days $(n=1), 7(n=7), 14(n=6)$ and $21(n=3)$ days. (7 days beta coefficient $=1.363, p$-value $=0.001 ; 14$ days beta coefficient $=1.325, p$-value $<0.001 ; 21$ days beta coefficient $=1.152$, $p$-value $=0.159$ ).

Conclusions: The meta-analysis suggests that bisphosphonate coatings of titanium implant surfaces may have beneficial effects on osteogenic behaviour of osteoblasts grown on titanium surfaces in vitro. Further studies are required to assess to which extent bisphosphonates coating might improve osseointegration in clinical situations.
\end{abstract}

Keywords: Dental implants, Surface modification, Bisphosphonates, Osseointegration, Osteoblasts, Alkaline phosphatase activity

\footnotetext{
* Correspondence: oleh.andrukhov@meduniwien.ac.at

'Division of Conservative Dentistry and Periodontology, University Clinic of

Dentistry, Medical University of Vienna, Sensengasse 2a, A-1090 Vienna,

Austria

Full list of author information is available at the end of the article
}

(c) The Author(s). 2020 Open Access This article is licensed under a Creative Commons Attribution 4.0 International License, which permits use, sharing, adaptation, distribution and reproduction in any medium or format, as long as you give appropriate credit to the original author(s) and the source, provide a link to the Creative Commons licence, and indicate if changes were made. The images or other third party material in this article are included in the article's Creative Commons licence, unless indicated otherwise in a credit line to the material. If material is not included in the article's Creative Commons licence and your intended use is not permitted by statutory regulation or exceeds the permitted use, you will need to obtain permission directly from the copyright holder. To view a copy of this licence, visit http://creativecommons.org/licenses/by/4.0/. The Creative Commons Public Domain Dedication waiver (http://creativecommons.org/publicdomain/zero/1.0/) applies to the data made available in this article, unless otherwise stated in a credit line to the data. 


\section{Background}

Nowadays, titanium dental implants demonstrate high long-term success rates and have become a standard treatment option for teeth replacement and prostheses support [1,2]. An essential requirement for stable implant anchoring is the osseointegration process, which was first described by Brånemark et al. in the late 1960s and is defined as a direct functional and structural connection between the implant surface and living bone [3]. About one decade later, the concept of dental implant surface properties as a paramount element in osseointegration was introduced by Albrektsson [4]. Earlier research efforts were mainly focused on dental implant geometry intending to improve clinical outcome and long-term success. Later the focus of interest was shifted towards topographical and chemical modifications of implant surfaces. These modifications aimed to improve osseointegration through enhancement of the underlying biological processes $[5,6]$. Surface characteristics like roughness or hydrophilicity affect proteins adsorption, cell adherence, proliferation, and differentiation, which are essential factors influencing the physiological processes during osseointegration [7, 8]. Titanium still is considered as a golden standard nowadays; however, alternative materials such as zirconia have raised interest due to almost similar osseointegration ability and hypothetically lower risk of peri-implantitis $[9,10]$. Besides topographical characteristics and hydrophilicity, surface coating with drugs, proteins, growth factors or specific agents is now extensively investigated as a future tool in implantology $[11,12]$.

Bisphosphonates are antiresorptive drugs that influence bone metabolism mainly via inhibition of osteoclast recruitment, differentiation, and bone resorption activity [13]. Frequent indications of bisphosphonates include osteoporosis, Paget's disease, skeletal metastases or osteogenesis imperfecta [14]. Members of the bisphosphonate family that are in common clinical use comprise alendronate, zoledronate, risedronate, ibandronate, and pamidronate [15]. After cellular uptake, bisphosphonates block the farnesyl pyrophosphate synthase, a key enzyme of the mevalonate pathway that is critical for osteoclast function [16]. Besides their inhibitory effect on osteoclasts and bone resorption, bisphosphonates may promote the processes of bone formation and enhance osteogenic differentiation of mesenchymal stem cells (MSCs) [17]. Bisphosphonates have been shown to support osseous wound healing and bone formation in the animal model [18, 19]. Dental implant bisphosphonate coatings are successfully applied as local drug delivery systems, demonstrating higher bone to implant contact (BIC) and peri-implant bone mineralization in the animal model [20, 21]. Bisphosphonate coated implants exhibit an increase in mechanical fixation in the human bone when compared to non-coated control [22]. Therefore, bisphosphonate coatings of titanium surfaces might also be beneficial for dental implant healing and osseointegration.

The formation of new bone around the dental implants is a complex process driven by osteoblasts and MSCs and precisely orchestrated by different cytokines and growth factors [23]. Alkaline phosphatase (ALP) is a widely used marker for early osteoblast differentiation in vitro and is crucial for bone formation [24, 25]. ALP increases the local concentration of inorganic phosphate and thus promotes mineralization processes [26]. Currently, literature investigating the impact of bisphosphonates on ALP in osteoblasts is contradictory, demonstrating either stimulating $[27,28]$ or inhibitory $[29$, 30] effects. The aim of this systematic review and metaanalysis was to assess the available in vitro evidence on the effect of bisphosphonate coated titanium surfaces on osteoblasts derived ALP activity. The significance of the effect of bisphosphonates coating on ALP activity was further tested by meta-analysis.

\section{Methods}

This systematic review and meta-analysis were performed following the PRISMA statement (Preferred Reporting Items for Systematic Reviews and MetaAnalyses) [31] and Cochrane handbook [32]. A PICO (Population, Intervention, Comparison, Outcome) strategy was defined to evaluate scientific evidence. Studies were considered eligible under the following criteria: In vitro evaluation of titanium surfaces (excluding animal studies and clinical studies) (P) that were coated with bisphosphonates (excluding studies adding bisphosphonates as a substrate during cell culture) (I), compared to non-treated control (C), regarding ALP activity in osteoblasts that have been cultured on the surfaces $(\mathrm{O})$.

\section{Search strategy}

A systematic literature search without time restriction was performed by two independent researchers using three electronic databases: PubMed/MEDLINE, Scopus, and ISI web of science. The language was limited to English. The following medical subject headings (MeSH) terms and keywords were used for search strategies in MEDLINE via PubMed: $(((()(($ bisphosphonate [MeSH Terms] OR bisphosphonate coating) OR phosphonate) OR alendronate) OR zoledronate) OR zoledronic acid) OR risedronate) OR ibandronate) OR pamidronate) AND (titanium OR titanium surface) AND ((alkaline phosphatase [MeSH Terms] OR alkaline phosphatase activity) OR ALP) AND (osteoblast [MeSH Terms] OR osteoblast-like cell). For ISI Web of Science and Scopus, the following search terms were used: "bisphosphonate" OR "bisphosphonate coating" OR "alendronate" OR 
"zoledronate" OR "zoledronic acid" OR "risedronate" OR "ibandronate" OR "pamidronate") AND ("titanium" OR "titanium surface") AND ("alkaline phosphatase" OR "alkaline phosphatase activity" OR "ALP") AND ("osteoblast" OR "osteoblast-like cell").

\section{Inclusion criteria}

Studies were included if they met the following criteria:

1. In vitro studies evaluating ALP activity in osteoblasts growing on titanium surfaces that were coated by bisphosphonates.

2. Studies written in English were included up until August 2019.

3. Sufficient data provided to perform calculations for the meta-analysis. In case data were not presented in the paper, the corresponding author was asked via e-mail to provide missing data. If there was no reply, measurement of the graphs by available online tools (GetData Graph Digitizer) that have been recommended by the Cochrane Handbook for Systematic Reviews of Interventions [33] was performed.

\section{Data extraction}

Data extraction was carried out independently by two researchers (CW and $\mathrm{OA})$. Each study was first checked regarding title, followed by screening of the abstracts and the full text. If the inclusion criteria were met, the following data were extracted for conduction of the meta-analysis: First author's name, year of publication, sample size per experiment, time of ALP activity measurement, cell type used for experiments, measure of variability, type of bisphosphonate used for coating, amount or concentration of bisphosphonate on titanium surface, alkaline phosphatase activity, coating specification. To ensure data quality, studies were checked for description of methodology and a clearly focused research question. Furthermore, the presence of the following parameters was reviewed in each study to perform quality assessment: stability of bisphosphonate coating, quality of ALP activity assessment, description of coating procedure, availability of original data, surface roughness parameters, contact angle measurement, appropriate statistical analysis, and performance of at least three repetitions. If the required information was stated within the paper, the study received one point on that specific parameter. Study quality was assessed according to the sum of points achieved: $1-3=$ high, $4-5=$ medium, $6-8=$ low quality. Any disagreements regarding study eligibility were discussed and solved by consulting a third researcher (XR).

\section{Statistical analysis}

For the meta-analysis, synthesis of the studies was carried out using the response ratio [34], which was calculated as the ratio of ALP activity value measured in the treatment group to those measured in the control group. This was done to avoid the effect of the variability of the absolute ALP activity values between the studies, which might depend on the used protocol and cell type. Calculations were done using the $\log$ of this ratio, but for the presentation, the results were back-transformed using the exponential function. Random-effects models were used to account for the high heterogeneity in the included studies. Additionally, multilevel models were necessary to account for including several groups of the same study in the analysis. Thus, meta-analytic multilevel random-effects models [35] were used, including a random effect for the studies. Tests and confidence intervals from these models presented are based on Wald statistics.

\section{Risk of publication bias}

Funnel plots on the log response ratio scale, as well as forest plots, were prepared. Publication bias was assessed by visually inspecting funnel plots and calculating Egger's test egger [36] and Kendall's tau [37] according to the suggestion of The PRISMA Statement for Reporting Systematic Reviews and Meta-Analyses [38]. Heterogenity was quantified using $\mathrm{I}^{2}$ as defined by Higgins \& Thompson 2002 [39]. All computations were done using $\mathrm{R}$ version 3.5.1.(R: A language and environment for statistical computing).

No further risk of bias was assessed as no validated bias risk assessment tool was available for in vitro studies.

\section{Results}

\section{Screening process and study selection}

The flowchart of the screening process is presented in Fig.1. The literature reviewing process revealed 42 studies: 14 from MEDLINE (PubMed), 16 from ISI Web of Science, 13 from Scopus electronic database. Twentytwo studies remained after duplicates removal. Of those, 11 studies had to be excluded as they did not match the following PICO criteria: P $(n=2), \mathrm{I}(n=6), \mathrm{O}$ $(n=3)$. Finally, 11 studies were enrolled for metaanalytic calculations.

\section{Descriptive analysis}

Table 1 shows the characteristics of the included studies for meta-analysis. All 11 studies were published between 2000 and 2019. In five studies experiments were performed with MG-63 human osteoblast-like cells [40, 41, 43, 45, 46], in three studies with MC3T3-E1 mouse osteoblast cells $[44,47,50]$, in two studies with 


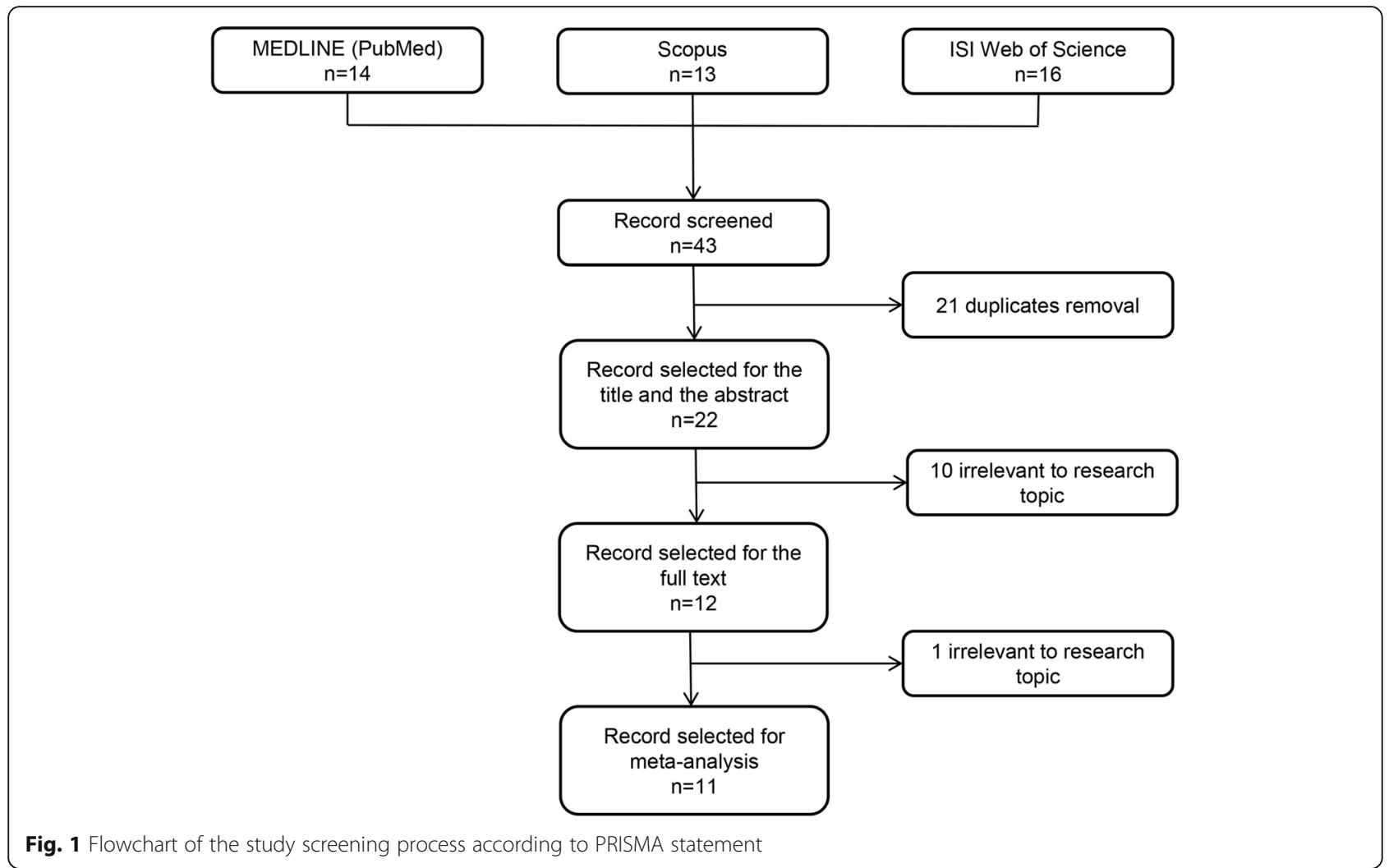

osteoblasts from rat calvaria $[48,49]$, and in one study with osteoblasts derived from primary human stem cells [42]. The sample size per experiment was ranging between 3 and 6 . ALP activity was measured after 3, 4, 7, $10,14,18$ or 21 days of cell culture; most studies $(n=7)$ performing experiments after 1 week. Nine studies used alendronate as coating, one study zoledronate, and one pamidronate.

Study quality assessment is presented in Table 2. According to the criteria applied, 8 studies were classified as medium quality, and 3 studies with low quality, respectively. Quantitative data required for the analysis were provided in one out of 11 studies [46], four authors provided data upon e-mail request [40-42, 48]. In the remaining six studies $[44,45,47,49,50]$, measurement of the graphs by available online software was performed because there was no response after e-mail request.

\section{Meta-analysis}

The results of the meta-analysis at days 7, 14, and 21 days are presented in Figs. 2, 3, and 4. At day 7, metaanalysis revealed a $36.3 \%$ higher ALP activity in osteoblasts following cell culture on bisphosphonate-coated titanium surfaces compared to control ( $\mathrm{T}$ vs $\mathrm{C}$ : beta coefficient $=1.363,95 \%$-CI from 1.128 to $1.648, p$-value $=$ 0.001; Fig. 2). Significant effect was still observed after
14 days of cell culture, exhibiting 32.5\% higher ALP activity in bisphosphonate-coated groups vs. non-treated titanium surfaces ( $\mathrm{T}$ vs. $\mathrm{C}$ : beta coefficient $=1.325,95 \%$ CI from 1.128 to $1.557, p$-value < 0.001; Fig. 3). The 21day model showed an about $15 \%$ higher ALP activity, but the effect was not statistically significant ( $\mathrm{T}$ vs. C: beta coefficient $=1.152,95 \%$-CI from 0.946 to $1.401, p$ value $=0.159$; Fig. 4 ).

The forest plots performed in the subgroups depending on the bisphosphonate type, coating, and cells are presented as additional files.

\section{Bias assessment}

Figure 5 shows the funnel plot referring to 7 th day. This plot exhibited no asymmetry (Kendall's tau is 0.23 , pvalue 0.306. $\mathrm{p}$-value from Egger's test is $0.412 . \mathrm{I}^{2}$ is 96.52). No further indication of relevant publication bias was found. The Funnel plots for days 14 and 21 exhibited a similar distribution (data not shown due to the low number of studies for these time points).

\section{Discussion}

Biological effects of bisphosphonates are mainly related to inhibition of osteoclasts activity, whereas their impact on osteoblasts is less obvious. According to current literature, in vitro data on the effect of bisphosphonates on 


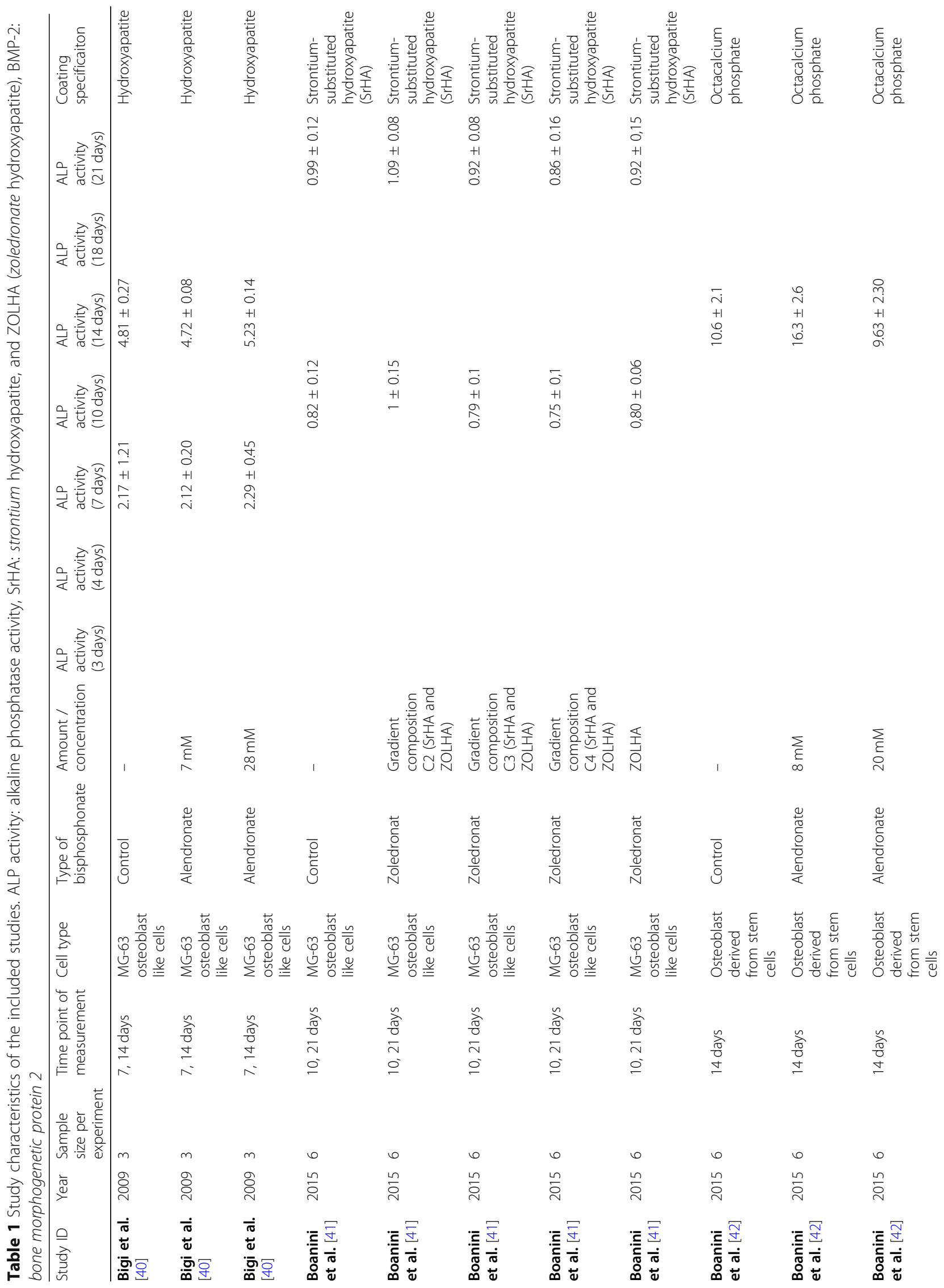




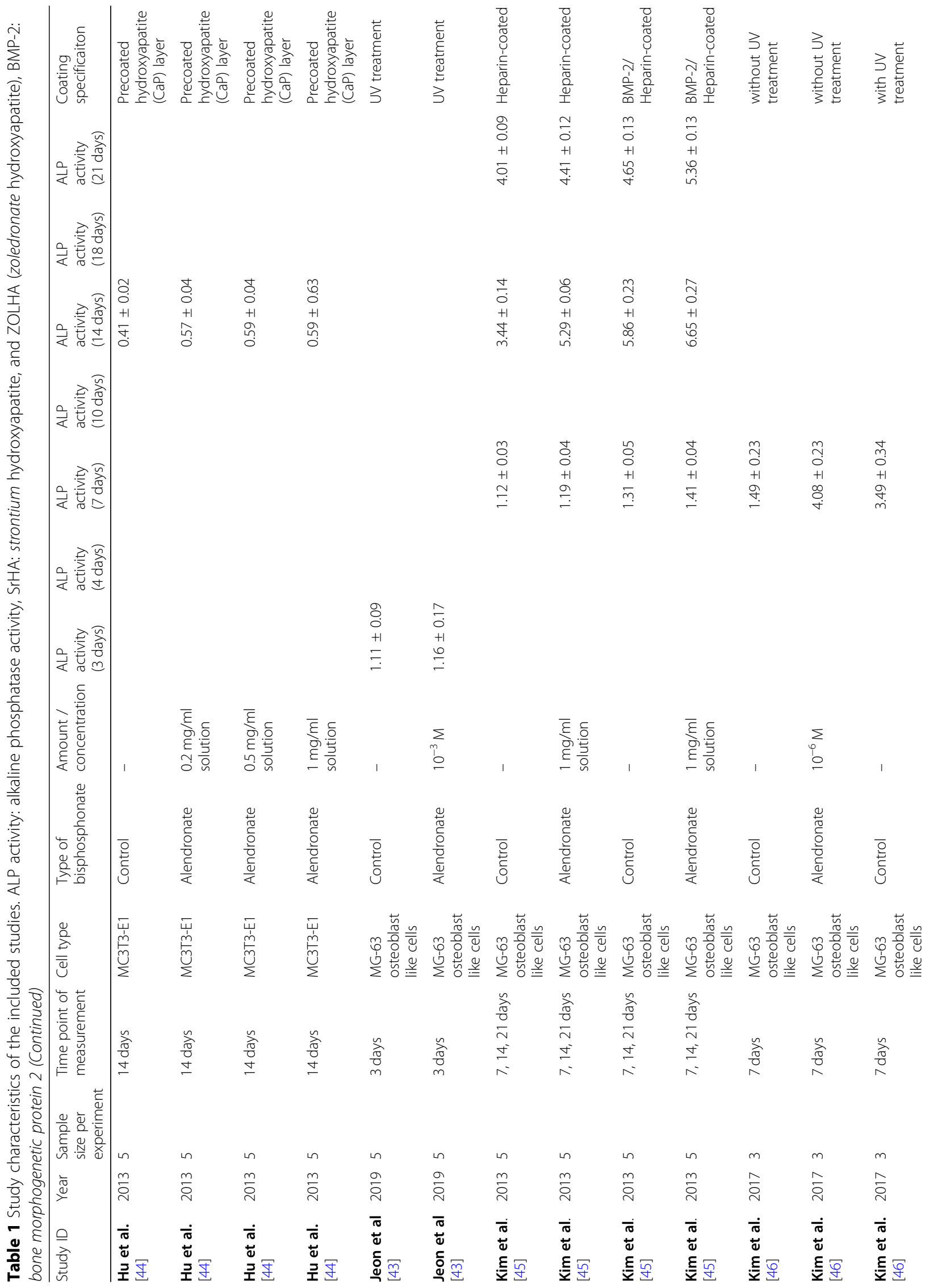




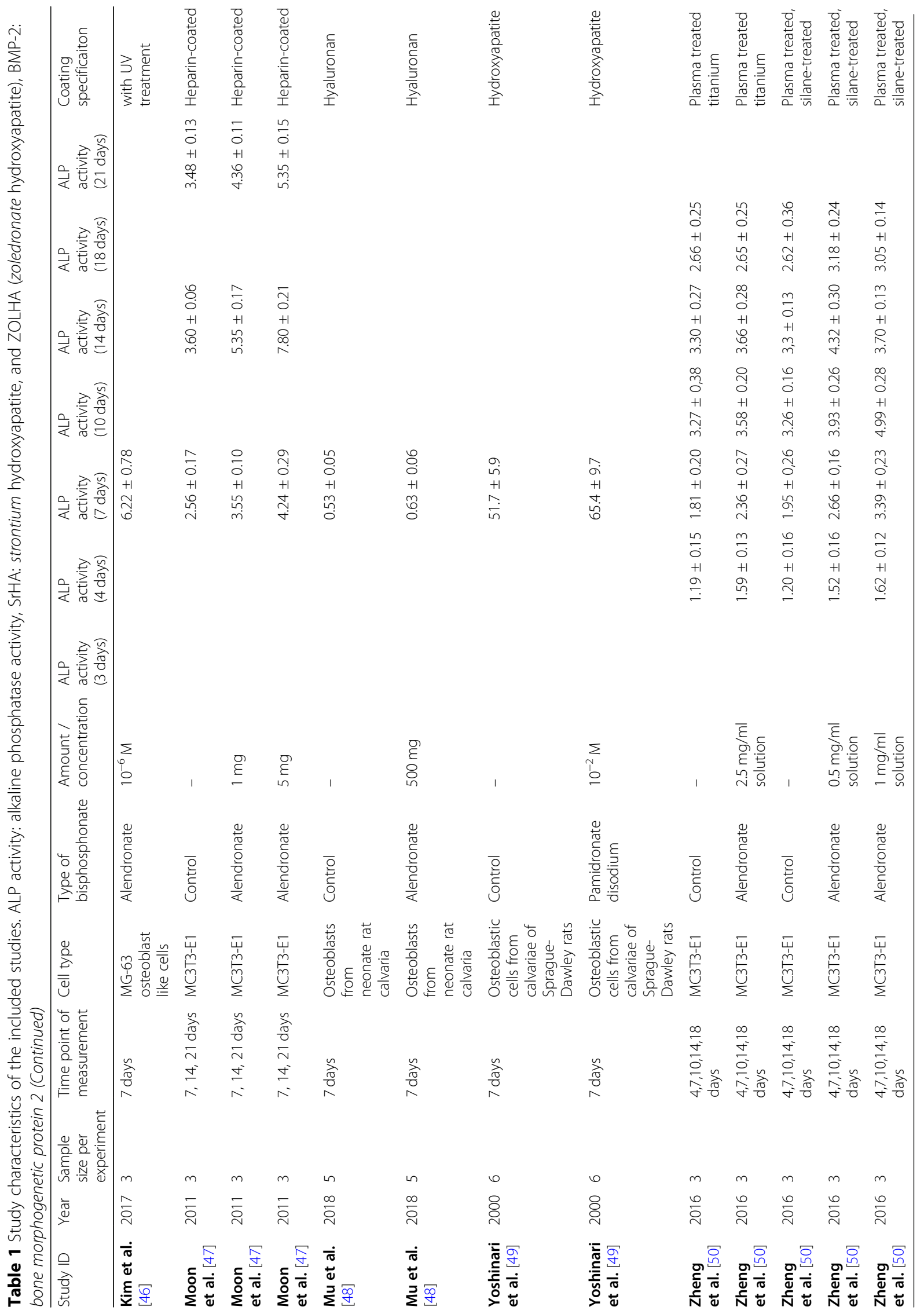


Table 2 Study quality assessment. 1) stability of bisphosphonate coating, 2) ALP measurement quality, 3) description of coating procedure, 4) availability of original data, 5) surface roughness parameters, 6) contact angle measurement, 7) appropriate statistical analysis, 8) performance of at least three repetitions per experiment

\begin{tabular}{|c|c|c|c|c|c|c|c|c|c|}
\hline & 1 & 2 & 3 & 4 & 5 & 6 & 7 & 8 & Study quality \\
\hline Bigi et al. [40] & No & No & Yes & Yes & Yes & No & Yes & Yes & Medium \\
\hline Boanini et al. [41] & No & No & Yes & Yes & Yes & No & Yes & No & Medium \\
\hline Boanini et al. [42] & Yes & No & Yes & Yes & Yes & No & Yes & No & Medium \\
\hline Hu et al. [44] & Yes & Yes & Yes & No & No & Yes & Yes & Yes & Low \\
\hline Jeon et al. [43] & No & Yes & Yes & No & No & No & Yes & Yes & Medium \\
\hline Kim et al. [45] & Yes & Yes & Yes & No & No & No & Yes & Yes & Medium \\
\hline Kim et al. [46] & No & Yes & Yes & Yes & No & No & Yes & No & Medium \\
\hline Moon et al. [47] & Yes & Yes & Yes & No & No & Yes & Yes & Yes & Low \\
\hline Mu et al. [48] & Yes & Yes & Yes & Yes & Yes & No & No & No & Medium \\
\hline Yoshinari et al. [49] & No & Yes & Yes & No & Yes & No & Yes & No & Medium \\
\hline Zheng et al. [50] & Yes & Yes & Yes & No & Yes & Yes & Yes & Yes & Low \\
\hline
\end{tabular}

ALP activity in osteoblasts are inconsistent [27, 29]. Similarly, some discrepancy exists among the studies investigating osteoblasts growing on bisphosphonate coated titanium surfaces: many studies indicate a significant increase in ALP activity following osteoblast culture, but some reports show no significant effect [40, 45, 48]. Our meta-analysis showed that bisphosphonate coatings significantly improve ALP activity suggesting that the biological effects of bisphosphonates might also be partially contributed by promoting osteoblasts function. These findings are further supported by a preclinical study demonstrating an enhancement of peri- implant bone density and an increased mechanical fixation of bisphosphonate-coated dental implants in the rat model [51]. Moreover, our results are also in agreement with clinical studies that report an improvement of osseointegration parameters, better implant stability, and reduced peri-implant bone loss after local bisphosphonates application [52, 53]. According to the present findings, studies included for meta-analysis that investigated alendronate or pamidronate coating of titanium surfaces increased ALP activity in osteoblasts. Interestingly, one study utilizing zoledronate as coating showed lower ALP activity results compared to untreated control [41]. This

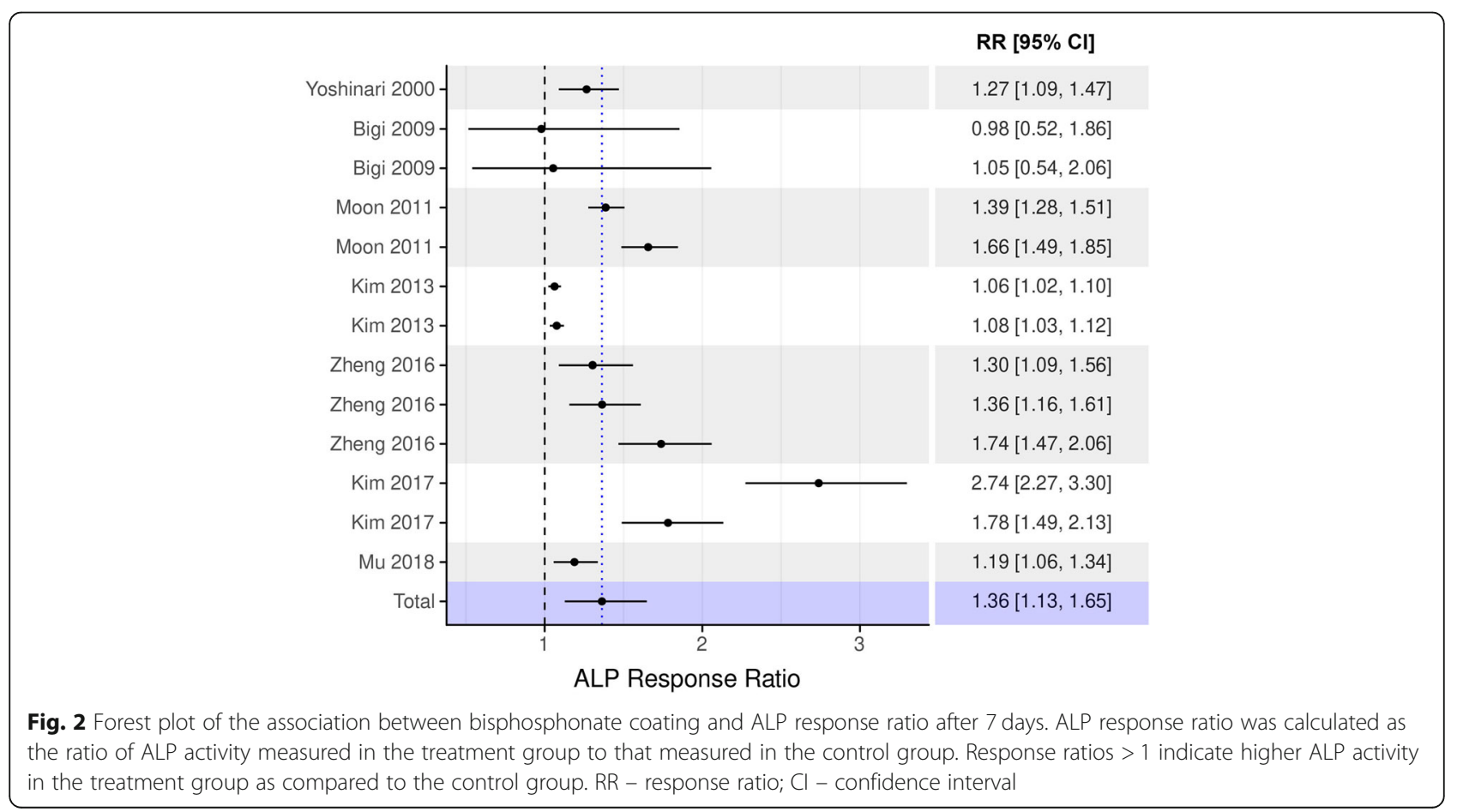




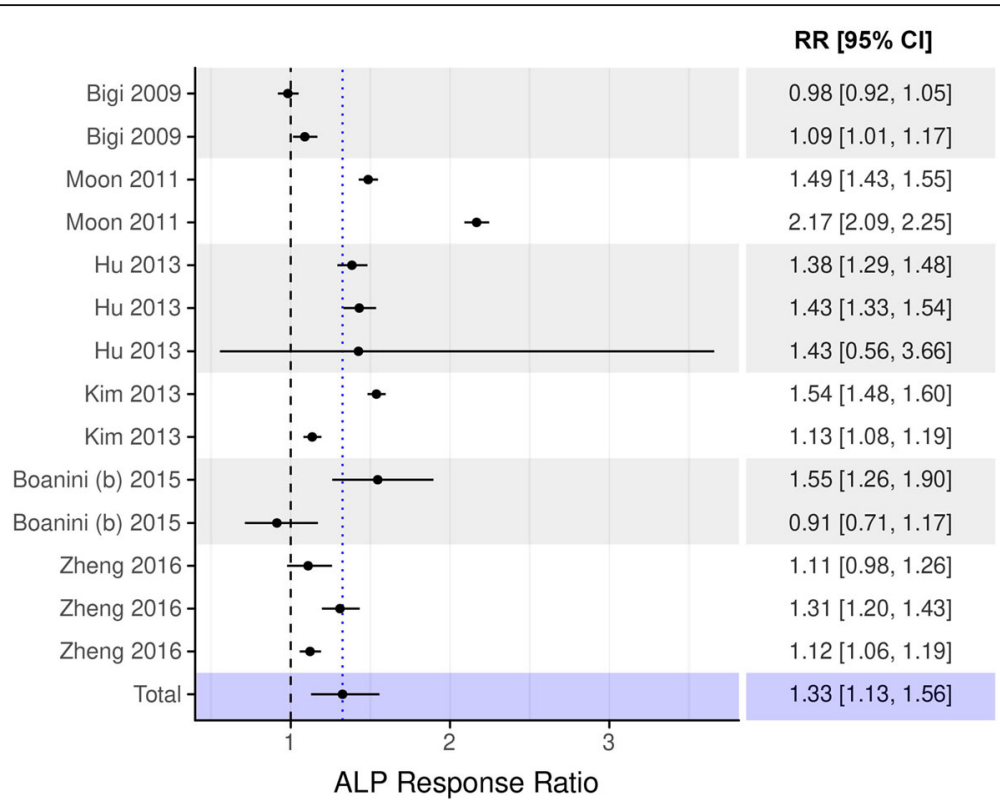

Fig. 3 Forest plot of the association between bisphosphonate coating and ALP response ratio after 14 days. ALP response ratio was calculated as the ratio of ALP activity measured in the treatment group to that measured in the control group. Response ratios $>1$ indicate higher ALP activity in the treatment group as compared to the control group. RR - response ratio; $\mathrm{Cl}$ - confidence interval

however might be explained by the fact that zoledronic acid might exert toxic effects on osteoblasts at higher concentrations.

Osseointegration is a complex process involving a plethora of different cells and mechanisms (36) and can only be partially reflected in in vitro settings. Alkaline phosphatase is an early marker of osteoblast differentiation and bone formation [54]. Further indicators for osteoblast differentiation comprise osteocalcin (OC), type I collagen, or runt-related transcription factor 2 (Runx2) expression [25, 55]. However, the ALP activity was the most frequently investigated parameter in

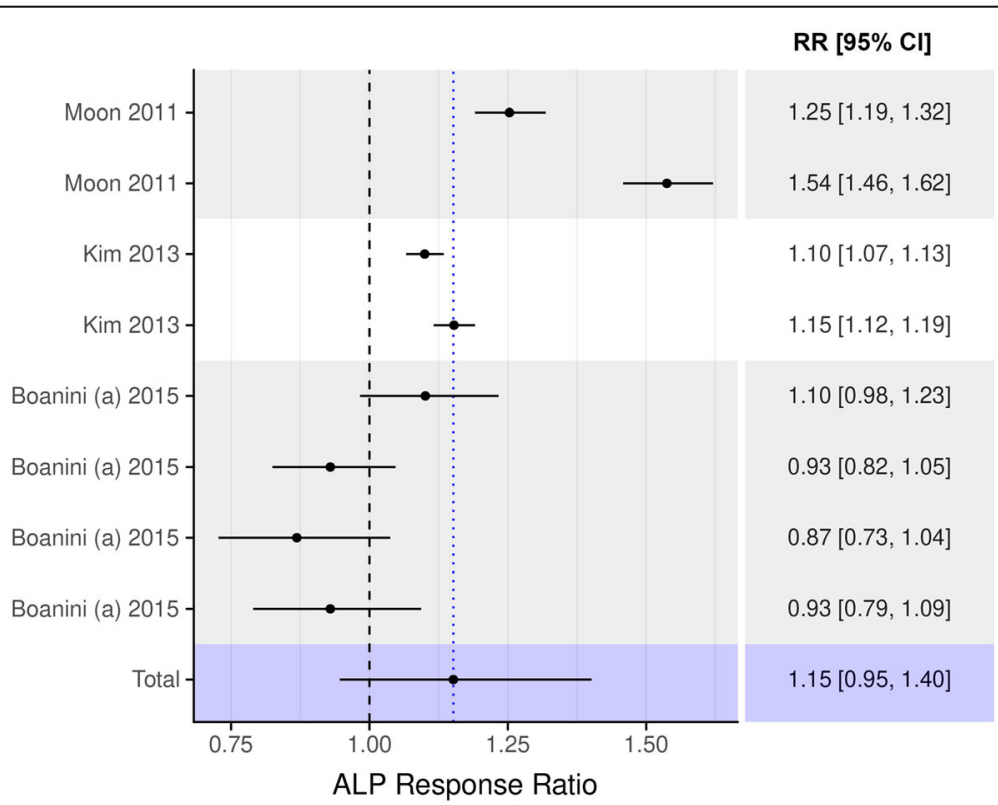

Fig. 4 Forest plot of the association between bisphosphonate coating and ALP response ratio after 21 days. ALP response ratio was calculated as the ratio of ALP activity measured in the treatment group to that measured in the control group. Response ratios $>1$ indicate higher ALP activity in the treatment group as compared to the control group. RR - response ratio; $\mathrm{Cl}$ - confidence interval 


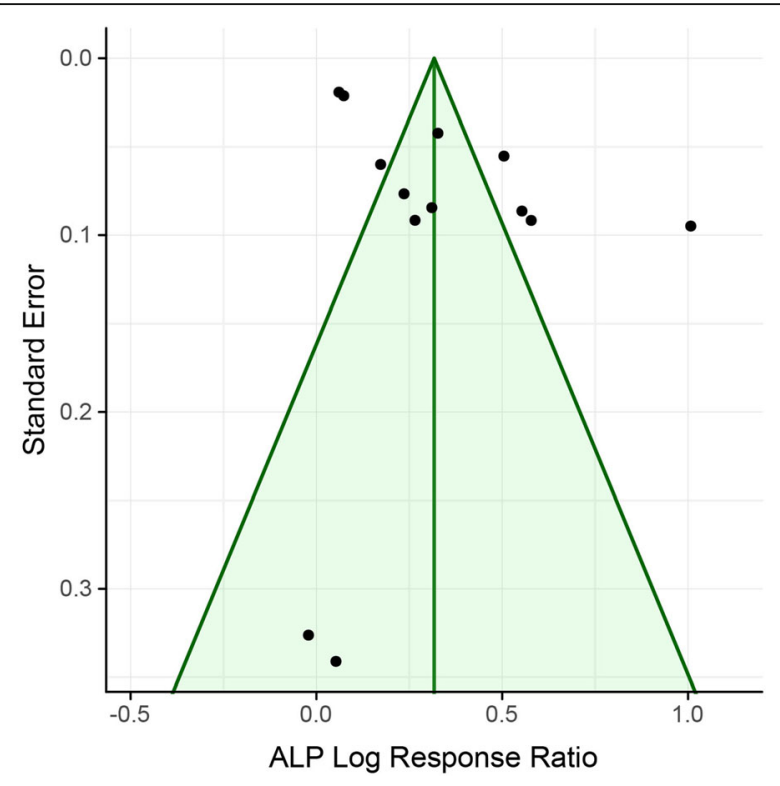

Fig. 5 Funnel plot of the association between bisphosphonate coating and ALP response ratio after 7 days

studies evaluating the osteogenic potential of titanium surface coatings with bisphosphonates. Among the studies included for meta-analysis, the expression of OC reflecting late osteogenic differentiation [56] was assessed in only four papers [40, 45, 47, 50], type I collagen expression was determined in three studies [40-42], whereas none of the studies performed evaluation of Runx2. Bisphosphonates coated implants demonstrated an increase in the expression of OC or type I collagen compared to control in all studies investigating these parameters and thus support our conclusion about a beneficial effect of bisphosphonate coating on osteogenic differentiation in vitro.

To assess publication bias, Egger's test, as well as Kendall's tau, were applied to evaluate funnel plot asymmetry. No funnel plot asymmetry was detected. To the best of the authors' knowledge, there is no validated bias risk assessment tool available for in vitro studies. However, it has to be considered that also other factors, such as differences in study quality or study heterogeneity, could lead to asymmetry in funnel plots.

One possible heterogeneity source is the use of four different cell types by the included studies. Some studies used MG-63 human osteosarcoma cells as osteoblasts model [40, 41, 43, 46, 57]. These cells largely reflect many properties of primary osteoblasts [58]. Other studies used the murine calvarial pre-osteoblast cell line MC3T3-E1 [44, 47, 50]. Although these cells are widely used in material research, a recent study suggests that the performance of these cells might be different in the different subclones [59]. Two studies used primary cells isolated from rat calvaria [48, 49], and one study used mesenchymal stem cells derived osteoblasts [42]. Although the primary cells most adequately reflect the physiological situation, their performance might depend on the donor and the isolation method [60].

There is no standardized, validated tool for the risk of bias assessment for in vitro studies, and therefore we could not perform bias assessment by the traditional algorithm. Instead, we focused on the question if and how some crucial parameters were controlled in the included studies. In eight out of 11 papers, the water contact angle measurements have not been performed [40-43, $45,46,48,49]$. We considered this parameter for study quality assessment because it reflects the hydrophilicity of titanium surfaces, which enhances the alkaline phosphatase expression of osteoblasts [61, 62]. Three studies demonstrated a significant decrease in contact angle after bisphosphonate coating procedure [44, 48, 50], which might contribute to the improved osteoblasts differentiation.

Titanium surface microscale roughness is a further important parameter influencing osteoblast response and ALP activity [8, 63]. Coating procedures utilizing diamond-like carbon (DLC) may alter titanium surface properties and influence surface topography and roughness parameters [64]. Five out of 11 included studies investigated the effect of bisphosphonate coating. They found no significant changes in roughness parameters, including an arithmetic average of the roughness profile (Ra) and further parameters such as root mean square roughness $(\mathrm{Rq})$ or maximum height of the profile (Rt) upon coating procedure [40-42, 48, 50].

In nine studies [40-42, 44, 46-50] titanium surface coating was done in combination with other components, such as hydroxyapatite (HA). Since HA is known to promote ALP activity in osteoblasts $[65,66]$, we did not consider pristine titanium but surfaces that were coated with the respective components as control. In terms of quality of ALP activity measurement, we regarded a normalisation of ALP data to cell number or protein amount as correct, instead of indicating absolute value. Such normalization of ALP activity measurement was performed in 8 studies [44-50].

It has to be also considered that coatings may exert biological effects only within a limited time period, as long as the drug or substance remains attached to the surface [67]. The assessment of the bisphosphonate coating stability in vitro was performed only by 6 out of 11 studies included in meta-analysis. The quantity of bisphosphonate released ranged from almost no measurable amounts [44] up to $40 \%$ of the initially immobilized substance [50]. The instability of coating could partially underlie the fact that its effect on the ALP activity was not significant after 21 days. Furthermore, also the 
bisphosphonate concentrations used for the coatings varied among the different studies, which could affect alkaline phosphatase activity to an unequal extent. It has to be taken into account that bisphosphonates at higher concentrations may also have cytotoxic effects on osteoblasts in vitro inhibit their viability $[68,69]$. One study observed concentration-dependent inhibition of osteoblasts viability on bisphosphonate coated surfaces [41]. In contrast, other studies showed beneficial effects of bisphosphonates on osteoblast proliferation/viability $[40,46]$.

An increased risk of developing osteonecrosis of the jaw (ONJ) is an undesirable side effect of systemic bisphosphonates therapy. Invasive surgical procedures like tooth extraction or dental implant placement have been demonstrated to increase the risk of ONJ development. The prevalence of ONJ induced by systemic bisphosphonates application depends on the bisphosphonates type, dosage and treatments duration [70]. However, the risk of ONJ upon local application of bisphosphonates coated surface needs to be further assessed. Local delivery might require lower amount of bisphosphonates compared to the systemic therapy and therefore be associated with the lower risk of ONJ.

A possible limitation of our study is that the search for grey literature was not included, as we considered quality assessment achieved by the peer-review process indispensable. This process assesses the experimental protocol, which is essential especially for in vitro studies. As another study limitation, it has to be taken into account that restriction to literature in English might bias the outcome of the meta-analysis. However, publications in English have undergone an international peer-review process, thus possibly meeting higher quality standards than reviewing on the national level. A further limitation of the present study is that its review protocol was not published in any platform, which could be considered less transparent compared to studies with published protocols.

\section{Conclusion}

In conclusion, our systematic review and meta-analysis showed that bisphosphonate coating of titanium surfaces exerts beneficial effects on osteogenic parameters in osteoblasts in vitro. Further studies are required to elucidate the underlying biological mechanisms that are initiated by bisphosphonate coatings of dental implants during the process of osseointegration and validate their clinical application in dental implantology.

\section{Supplementary information}

Supplementary information accompanies this paper at https://doi.org/10. 1186/s12903-020-01089-4.

Additional file 1. Forest plots depending on type of bisphosphonate, coating specification, and cells for ALP activity after 7 days.
Additional file 2. Forest plots depending on type of bisphosphonate, coating specification, and cells for ALP activity after 7 days.

Additional file 3. Forest plots depending on type of bisphosphonate, coating specification, and cells for ALP activity after 7 days.

\section{Abbreviations}

ALP: Alkaline phosphatase; BIC: Bone to implant contact; DLC: Diamond-like carbon; HA: Hydroxyapatite; MSCs: Mesenchymal stem cells; OC: Osteocalcin; ONJ: Osteonecrosis of the jaw; Ra: Roughness profile; Rq: Root mean square roughness; Rt: Maximum height of the profile; Runx2: Runt-related transcription factor 2

\section{Acknowledgements}

Not applicable.

\section{Authors' contributions}

CW: research concept and design, collection and/or assembly of data, data analysis and interpretation, writing the article. SL: data analysis and interpretation. AM: critical revision of the article, final approval of article. OA: research concept and design, collection and/or assembly of data, data analysis and interpretation, critical revision of the article. XR: critical revision of the article, final approval of article. All authors read and approved the final manuscript.

\section{Funding}

Study was self-founded.

\section{Availability of data and materials}

The authors declare that they are in possession of complete data on the basis of which calculations have been performed. The authors will make data available upon request. For this purpose, interested party is suggested to contact authors'institution directly:

Division of Conservative Dentistry and Periodontology, University Clinic of Dentistry, Medical University of Vienna, Sensengasse 2a, 1090 Vienna, Austria.

Ethics approval and consent to participate

Not applicable.

Consent for publication

Not applicable.

\section{Competing interests}

The authors declare that they have no competing interests.

\section{Author details}

'Division of Conservative Dentistry and Periodontology, University Clinic of Dentistry, Medical University of Vienna, Sensengasse 2a, A-1090 Vienna, Austria. ${ }^{2}$ Division of Oral Surgery, University Clinic of Dentistry, Medical University of Vienna, Vienna, Austria. ${ }^{3}$ Austrian Cluster for Tissue Regeneration, Vienna, Austria.

Received: 13 October 2019 Accepted: 26 March 2020

Published online: 25 April 2020

\section{References}

1. Karoussis IK, Brägger U, Salvi GE, Bürgin W, Lang NP. Effect of implant design on survival and success rates of titanium oral implants: a 10-year prospective cohort study of the ITI dental implant system. Clin Oral Implants Res. 2004;15(1):8-17.

2. Blanes RJ, Bernard JP, Blanes ZM, Belser UC. A 10-year prospective study of ITI dental implants placed in the posterior region. I: clinical and radiographic results. Clin Oral Implants Res. 2007;18(6):699-706.

3. Brånemark PI, Adell R, Breine U, Hansson BO, Lindström J, Ohlsson A. Intraosseous anchorage of dental prostheses. I. Experimental studies. Scand J Plast Reconstr Surg. 1969:3(2):81-100.

4. Albrektsson T, Brånemark PI, Hansson HA, Lindström J. Osseointegrated titanium implants. Requirements for ensuring a long-lasting, direct bone-toimplant anchorage in man. Acta Orthop Scand. 1981;52(2):155-70. 
5. Smeets R, Stadlinger B, Schwarz F, Beck-Broichsitter B, Jung O, Precht C, Kloss F, Gröbe A, Heiland M, Ebker T. Impact of dental implant surface modifications on Osseointegration. Biomed Res Int. 2016;2016:6285620.

6. Rupp F, Liang L, Geis-Gerstorfer J, Scheideler L, Huttig F. Surface characteristics of dental implants: a review. Dent Mater. 2018;34(1):40-57.

7. Blatt S, Pabst AM, Schiegnitz E, Hosang M, Ziebart T, Walter C, Al-Nawas B, Klein MO. Early cell response of osteogenic cells on differently modified implant surfaces: sequences of cell proliferation, adherence and differentiation. J Craniomaxillofac Surg. 2018;46(3):453-60.

8. Andrukhov O, Huber R, Shi B, Berner S, Rausch-Fan X, Moritz A, Spencer ND, Schedle A. Proliferation, behavior, and differentiation of osteoblasts on surfaces of different microroughness. Dent Mater. 2016;32(11):1374-84.

9. Kohal RJ, Bächle M, Att W, Chaar S, Altmann B, Renz A, Butz F. Osteoblast and bone tissue response to surface modified zirconia and titanium implant materials. Dent Mater. 2013;29(7):763-76.

10. Rezaei NM, Hasegawa M, Ishijima M, Nakhaei K, Okubo T, Taniyama T, Ghassemi A, Tahsili T, Park W, Hirota M, et al. Biological and osseointegration capabilities of hierarchically (meso-/micro-/nano-scale) roughened zirconia. Int J Nanomedicine. 2018;13:3381-95.

11. Coelho PG, Jimbo R, Tovar N, Bonfante EA. Osseointegration: hierarchical designing encompassing the macrometer, micrometer, and nanometer length scales. Dent Mater. 2015;31(1):37-52.

12. Le Guéhennec L, Soueidan A, Layrolle P, Amouriq Y. Surface treatments of titanium dental implants for rapid osseointegration. Dent Mater. 2007;23(7): 844-54.

13. Russell RG, Rogers MJ. Bisphosphonates: from the laboratory to the clinic and back again. Bone. 1999;25(1):97-106.

14. Licata AA. Discovery, clinical development, and therapeutic uses of bisphosphonates. Ann Pharmacother. 2005;39(4):668-77.

15. Watts NB. Long-term risks of bisphosphonate therapy. Arq Bras Endocrinol Metabol. 2014;58(5):523-9.

16. Rogers MJ, Crockett JC, Coxon FP, Mönkkönen J. Biochemical and molecular mechanisms of action of bisphosphonates. Bone. 2011;49(1):34-41.

17. Inoue $Y$, Hisa I, Seino S, Kaji H. Alendronate induces mineralization in mouse osteoblastic MC3T3-E1 cells: regulation of mineralization-related genes. Exp Clin Endocrinol Diabetes. 2010;118(10):719-23.

18. Toker H, Ozdemir H, Ozer H, Eren K. Alendronate enhances osseous healing in a rat calvarial defect model. Arch Oral Biol. 2012;57(11):1545-50.

19. Alp YE, Taskaldiran A, Onder ME, Karahan S, Kocyigit ID, Atil F, Tekin U. Effects of local low-dose alendronate injections into the distraction gap on new bone formation and distraction rate on distraction Osteogenesis. J Craniofac Surg. 2017;28(8):2174-8

20. Alenezi A, Chrcanovic B, Wennerberg A. Effects of local drug and chemical compound delivery on bone regeneration around dental implants in animal models: a systematic review and meta-analysis. Int J Oral Maxillofac Implants. 2018;33(1):e1-e18.

21. Karlsson J, Martinelli A, Fathali HM, Bielecki J, Andersson M. The effect of alendronate on biomineralization at the bone/implant interface. J Biomed Mater Res A. 2016;104(3):620-9.

22. Abtahi J, Tengvall P, Aspenberg P. A bisphosphonate-coating improves the fixation of metal implants in human bone. A randomized trial of dental implants. Bone. 2012;50(5):1148-51.

23. Lotz EM, Berger MB, Schwartz Z, Boyan BD. Regulation of osteoclasts by osteoblast lineage cells depends on titanium implant surface properties. Acta Biomater. 2018;68:296-307.

24. Christenson RH. Biochemical markers of bone metabolism: an overview. Clin Biochem. 1997;30(8):573-93.

25. Aubin JE, Liu F, Malaval L, Gupta AK. Osteoblast and chondroblast differentiation. Bone. 1995;17(2 Suppl):77S-83S

26. Orimo $\mathrm{H}$. The mechanism of mineralization and the role of alkaline phosphatase in health and disease. J Nippon Med Sch. 2010;77(1):4-12.

27. Corrado A, Neve A, Maruotti N, Gaudio A, Marucci A, Cantatore FP. Dosedependent metabolic effect of zoledronate on primary human osteoblastic cell cultures. Clin Exp Rheumatol. 2010;28(6):873-9.

28. Ma X, Xu Z, Ding S, Yi G, Wang Q. Alendronate promotes osteoblast differentiation and bone formation in ovariectomy-induced osteoporosis through interferon- $\beta /$ signal transducer and activator of transcription 1 pathway. Exp Ther Med. 2018;15(1):182-90.

29. Marolt D, Cozin M, Vunjak-Novakovic G, Cremers S, Landesberg R. Effects of pamidronate on human alveolar osteoblasts in vitro. J Oral Maxillofac Surg. 2012;70(5):1081-92.
30. Huang X, Huang S, Guo F, Xu F, Cheng P, Ye Y, Dong Y, Xiang W, Chen A. Dose-dependent inhibitory effects of zoledronic acid on osteoblast viability and function in vitro. Mol Med Rep. 2016;13(1):613-22.

31. Moher D, Shamseer $L$, Clarke $M$, Ghersi D, Liberati A, Petticrew M, Shekelle $P$, Stewart LA, Group P-P. Preferred reporting items for systematic review and meta-analysis protocols (PRISMA-P) 2015 statement. Syst Rev. 2015;4:1.

32. JPT H, S G: Cochrane Handbook for Systematic Reviews of Interventions Version 5.1.0 [updated March 2011]. In.: The Cochrane Collaboration; 2011.

33. Higgins JPT, Thomas J: Cochrane Handbook for Systematic Reviews of Interventions: Edition 2. In.; 2019: 728.

34. Borenstein M, Hedges LV, Higgins JPT, Rothstein HR: Introduction to MetaAnalysis; 2009.

35. Wolfgang V. Conducting meta-analyses in R withthe metafor package. J Stat Softw. 2011;363:1-48.

36. Sterne JAC, Egger M: Regression methods to detect publication and other bias in meta-analysis. In: Publication bias in meta-analysis: Prevention, assessment, and adjustments. edn. Edited by R. RH, J. SA, M. B. Chichester, England; 2005: 99--110.

37. Begg CB, Mazumdar M. Operating characteristics of a rank correlation test for publication bias. Biometrics. 1994;50(4):1088-101.

38. Liberati A, Altman DG, Tetzlaff J, Mulrow C, Gøtzsche PC, loannidis JP, Clarke M, Devereaux PJ, Kleijnen J, Moher D. The PRISMA statement for reporting systematic reviews and meta-analyses of studies that evaluate health care interventions: explanation and elaboration. PLoS Med. 2009;6(7):e1000100.

39. Higgins JP, Thompson SG. Quantifying heterogeneity in a meta-analysis. Stat Med. 2002;21(11):1539-58.

40. Bigi A, Boanini E, Capuccini C, Fini M, Mihailescu IN, Ristoscu C, Sima F, Torricelli P. Biofunctional alendronate-hydroxyapatite thin films deposited by matrix assisted pulsed laser evaporation. Biomaterials. 2009;30(31):6168-77.

41. Boanini E, Torricelli P, Sima F, Axente E, Fini M, Mihailescu IN, Bigi A. Strontium and zoledronate hydroxyapatites graded composite coatings for bone prostheses. J Colloid Interface Sci. 2015;448:1-7.

42. Boanini E, Torricelli P, Forte L, Pagani S, Mihailescu N, Ristoscu C, Mihailescu IN, Bigi A. Antiresorption implant coatings based on calcium alendronate and octacalcium phosphate deposited by matrix assisted pulsed laser evaporation. Colloids Surf B Biointerfaces. 2015;136:449-56.

43. Jeon C, Oh KC, Park KH, Moon HS. Effects of ultraviolet treatment and alendronate immersion on osteoblast-like cells and human gingival fibroblasts cultured on titanium surfaces. Sci Rep. 2019;9(1):2581.

44. Hu X, Neoh KG, Shi Z, Kang ET, Wang W. An in vitro assessment of fibroblast and osteoblast response to alendronate-modified titanium and the potential for decreasing fibrous encapsulation. Tissue Eng Part A. 2013;19(17-18):1919-30.

45. Eun KS, Young-Pil Y, Kyeongsoon P, Hak-Jun K, Deok-Won L, Wook KJ, Hyeok YD, Hun SD. The Effects of Functionalized Titanium with Alendronate and Bone Morphogenic Protein-2 for Improving Osteoblast Activity. Tissue Eng Regen Med. 2013;10(6):353-61.

46. Kim HS, Lee Jl, Yang SS, Kim BS, Kim BC, Lee J. The effect of alendronate soaking and ultraviolet treatment on bone-implant interface. Clin Oral Implants Res. 2017;28(9):1164-72.

47. Moon HJ, Yun YP, Han CW, Kim MS, Kim SE, Bae MS, Kim GT, Choi YS, Hwang EH, Lee JW, et al. Effect of heparin and alendronate coating on titanium surfaces on inhibition of osteoclast and enhancement of osteoblast function. Biochem Biophys Res Commun. 2011;413(2):194-200.

48. Mu C, Hu Y, Huang L, Shen X, Li M, Li L, Gu H, Yu Y, Xia Z, Cai K. Sustained raloxifene release from hyaluronan-alendronate-functionalized titanium nanotube arrays capable of enhancing osseointegration in osteoporotic rabbits. Mater Sci Eng C Mater Biol Appl. 2018;82:345-53.

49. Yoshinari M, Oda Y, Ueki H, Yokose S. Immobilization of bisphosphonates on surface modified titanium. Biomaterials. 2001;22(7):709-15.

50. Zheng $D$, Neoh KG, Kang ET. Immobilization of alendronate on titanium via its different functional groups and the subsequent effects on cell functions. J Colloid Interface Sci. 2017:487:1-11.

51. Peter B, Pioletti DP, Laïb S, Bujoli B, Pilet P, Janvier P, Guicheux J, Zambelli PY, Bouler JM, Gauthier O. Calcium phosphate drug delivery system: influence of local zoledronate release on bone implant osteointegration. Bone. 2005;36(1):52-60.

52. Khamis AK, Elsharkawy S. The influence of local delivery of bisphosphonate on osseointegration of dental implants. Evid Based Dent. 2018;19(3):82-3.

53. Guimarães MB, Antes TH, Dolacio MB, Pereira DD, Marquezan M. Does local delivery of bisphosphonates influence the osseointegration of titanium 
implants? A systematic review. Int J Oral Maxillofac Surg. 2017;46(11):142936.

54. Harrison G, Shapiro IM, Golub EE. The phosphatidylinositol-glycolipid anchor on alkaline phosphatase facilitates mineralization initiation in vitro. J Bone Miner Res. 1995;10(4):568-73.

55. Komori T. Requisite roles of Run $\times 2$ and $\mathrm{Cbfb}$ in skeletal development. J Bone Miner Metab. 2003;21(4):193-7.

56. Lian JB, Stein GS. Concepts of osteoblast growth and differentiation: basis for modulation of bone cell development and tissue formation. Crit Rev Oral Biol Med. 1992;3(3):269-305.

57. Kim SE, Suh DH, Yun YP, Lee JY, Park K, Chung JY, Lee DW. Local delivery of alendronate eluting chitosan scaffold can effectively increase osteoblast functions and inhibit osteoclast differentiation. J Mater Sci Mater Med. 2012; 23(11):2739-49.

58. Pautke C, Schieker M, Tischer T, Kolk A, Neth P, Mutschler W, Milz S. Characterization of osteosarcoma cell lines MG-63, Saos-2 and U-2 OS in comparison to human osteoblasts. Anticancer Res. 2004;24(6):3743-8.

59. Hwang PW, Horton JA. Variable osteogenic performance of MC3T3-E1 subclones impacts their utility as models of osteoblast biology. Sci Rep. 2019;9(1):8299

60. Jonsson KB, Frost A, Nilsson O, Ljunghall S, Ljunggren $\mathrm{O}$. Three isolation techniques for primary culture of human osteoblast-like cells: a comparison. Acta Orthop Scand. 1999;70(4):365-73.

61. Sedlaczek J, Lohmann CH, Lotz EM, Hyzy SL, Boyan BD, Schwartz Z. Effects of low-frequency ultrasound treatment of titanium surface roughness on osteoblast phenotype and maturation. Clin Oral Implants Res. 2017;28(10): e151-8

62. Zhang Y, Andrukhov O, Berner S, Matejka M, Wieland M, Rausch-Fan X, Schedle A. Osteogenic properties of hydrophilic and hydrophobic titanium surfaces evaluated with osteoblast-like cells (MG63) in coculture with human umbilical vein endothelial cells (HUVEC). Dent Mater. 2010;26(11): 1043-51.

63. Yamamura K, Miura T, Kou I, Muramatsu T, Furusawa M, Yoshinari M. Influence of various superhydrophilic treatments of titanium on the initial attachment, proliferation, and differentiation of osteoblast-like cells. Dent Mater J. 2015;34(1):120-7.

64. Starý V, Douděrová $M$, Bačáková L. Influence of surface roughness of carbon materials on human osteoblast-like cell growth. J Biomed Mater Res A. 2014;102(6):1868-79

65. Costa DO, Prowse PD, Chrones T, Sims SM, Hamilton DW, Rizkalla AS, Dixon SJ. The differential regulation of osteoblast and osteoclast activity by surface topography of hydroxyapatite coatings. Biomaterials. 2013;34(30):7215-26.

66. Deng B, Bruzzaniti A, Cheng GJ. Enhancement of osteoblast activity on nanostructured NiTi/hydroxyapatite coatings on additive manufactured NiTi metal implants by nanosecond pulsed laser sintering. Int J Nanomedicine. 2018;13:8217-30.

67. Albrektsson T. Hydroxyapatite-coated implants: a case against their use. J Oral Maxillofac Surg. 1998;56(11):1312-26.

68. Sun J, Song F, Zhang W, Sexton BE, Windsor LJ. Effects of alendronate on human osteoblast-like MG63 cells and matrix metalloproteinases. Arch Oral Biol. 2012;57(6):728-36.

69. Pons-Fuster López E, Seoane Leston J, López Jornet P. Epigallocatechin-3gallate reduces damage to osteoblast-like cells treated with Zoledronic acid. Arch Oral Biol. 2018:94:27-32.

70. Gupta S, Gupta H, Mandhyan D, Srivastava S. Bisphophonates related osteonecrosis of the jaw. Natl J Maxillofac Surg. 2013;4(2):151-8.

\section{Publisher's Note}

Springer Nature remains neutral with regard to jurisdictional claims in published maps and institutional affiliations.

\section{Ready to submit your research? Choose BMC and benefit from}

- fast, convenient online submission

- thorough peer review by experienced researchers in your field

- rapid publication on acceptance

- support for research data, including large and complex data types

- gold Open Access which fosters wider collaboration and increased citations

- maximum visibility for your research: over $100 \mathrm{M}$ website views per year

At BMC, research is always in progress.

Learn more biomedcentral.com/submissions 